\title{
Screening Molecules for Control of Citrus Huanglongbing Using an Optimized Regeneration System for 'Candidatus Liberibacter asiaticus'-Infected Periwinkle (Catharanthus roseus) Cuttings
}

\author{
Muqing Zhang, Yongping Duan, Lijuan Zhou, William W. Turechek, Ed Stover, and Charles A. Powell
}

First and sixth authors: IFAS-IRREC, University of Florida, Fort Pierce 34945; and second, third, fourth, and fifth authors: United States Department of Agriculture-Agricultural Research Service-USHRL, Fort Pierce, FL 34945.

Accepted for publication 1 December 2009.

\begin{abstract}
Zhang, M. Q., Duan, Y. P., Zhou, L. J., Turechek, W. W., Stover, E., and Powell, C. A. 2010. Screening molecules for control of citrus huanglongbing using an optimized regeneration system for 'Candidatus Liberibacter asiaticus'-infected periwinkle (Catharanthus roseus) cuttings. Phytopathology 100:239-245.

Citrus huanglongbing is one of the most destructive diseases of citrus worldwide. The disease is associated with three different species of 'Candidatus Liberibacter', of which ' $\mathrm{Ca}$. L. asiaticus' is the most widely distributed. An optimized system using ' $\mathrm{Ca}$. L. asiaticus'-infected periwinkle cuttings was developed to screen chemical compounds effective for controlling the bacterial population while simultaneously assessing their phytotoxicity. The optimal regeneration conditions were determined to be the use of vermiculite as a growth medium for the cuttings, and a

fertilization routine using half-strength Murashige and Tucker medium supplemented with both naphthalene acetic acid $(4 \mu \mathrm{g} / \mathrm{ml})$ and indole-3butyric acid $(4 \mu \mathrm{g} / \mathrm{ml})$. This system allowed a plant regeneration rate of $60.6 \%$ for ' $\mathrm{Ca}$. L. asiaticus'-infected cuttings in contrast to the $<1 \%$ regeneration rate with water alone. Two chemical agents, penicillin $G$ sodium and 2,2-dibromo-3-nitrilopropionamide (DBNPA), were found to be effective at eliminating or suppressing the ' $\mathrm{Ca}$. L. asiaticus' bacterium in this periwinkle regeneration system. When treated with penicillin $\mathrm{G}$ sodium at $50 \mu \mathrm{g} / \mathrm{ml}$, all plants regenerated from ' $\mathrm{Ca}$. L. asiaticus'-infected cuttings were ' $\mathrm{Ca}$. L. asiaticus' negative as determined by both nested polymerase chain reaction (PCR) and quantitative real-time PCR. In addition, DBNPA was also able to significantly reduce the percentage of ' $\mathrm{Ca}$. L. asiaticus'-positive plants and the titer of the ' $\mathrm{Ca}$. L. asiaticus' bacterium at $200 \mu \mathrm{l} /$ liter.
\end{abstract}

Citrus huanglongbing (HLB) (also known as citrus greening) is one of the most destructive diseases of citrus worldwide. The disease is associated with three species of the phloem-limited, gram-negative, fastidious $\alpha$-proteobacteria: 'Candidatus Liberibacter asiaticus', ' $\mathrm{Ca}$ L. africanus', and ' $\mathrm{Ca}$. L. americanus' (11, $25,31,42)$. Of the three species associated with HLB, ' $C a$. L. asiaticus' is the most widely distributed. The finding of HLB in 2004 in São Paulo, Brazil $(11,12,42)$ and in 2005 in Florida, United States (20) has caused serious concerns because these two countries account for approximately one-third of the world's citrus production. To date, the disease has spread to all 33 Florida citrus-producing counties, threatening not only the $\$ 9$ billion dollar Florida citrus industry but citrus production as a whole in the United States (IMPACT, spring 2008).

HLB is extremely difficult to manage because all commercial citrus species and cultivars appear susceptible, regardless of rootstock $(30,36)$, and no cure is currently available for infected trees. Control and management measures are limited to the use of disease-free propagating stock, roguing of symptomatic trees, and chemical or biological control of the vectors $(4-6,32)$. Approximately 100 million infected citrus trees have been destroyed by the disease throughout Asia, with an additional 1 million trees eliminated in Brazil since the first report of the disease in São Paulo in 2004 (20). With the finding that prokaryotic organisms were associated with HLB (25), an effort to control disease in existing orchards was made in several countries or regions, including

Corresponding author: C. A. Powell; E-mail address: capowell@ufl.edu

doi:10.1094/PHYTO-100-3-0239

This article is in the public domain and not copyrightable. It may be freely reprinted with customary crediting of the source. The American Phytopathological Society, 2010
South Africa, India, Indonesia, and Taiwan, by injecting trees with antibiotics $(3,35,38)$. Several researchers reported initial success in largely reversing the symptoms of HLB. In addition, polymerase chain reaction (PCR) methods were not available to test for low bacteria levels and most plants were field treated with continual reexposure to HLB, making it impossible to verify pathogen elimination. The only commercially applied therapeutic treatment for HLB was the use of tetracycline, which is bacteriostatic rather than bactericidal, in Reunion Island's orchards $(3,4,8)$. Regular applications of tetracycline were necessary for continuous suppression of disease but frequent applications are not cost effective and may lead to the emergence of antibiotic-resistant bacteria.

Although it would be ideal to have a cost-effective field treatment to cure HLB-affected trees, it may be even more important to develop techniques to ensure that planting material is HLBbacteria-free and to permit rescue of valuable HLB-affected germplasm. Therefore, an approach for rapidly screening and evaluating antimicrobial compounds is needed to identify effective compounds and develop therapeutic treatments which can be implemented in citrus production. Because the bacteria associated with HLB are fastidious, a screening technology allowing rapid plant regeneration from HLB-affected explants is fundamental for screening and assessing such anti-Liberibacter compounds.

HLB-affected citrus cuttings are difficult to root and regenerate. Periwinkle, an alternate experimental host of the HLB bacteria $(18,19)$, is a preferred model plant because periwinkle plants not only grow quickly but also allow the bacteria to multiply well; therefore, the infected periwinkle plants could be quickly produced by grafting and dodder transmission (19). In this article, we describe an optimized screening system using ' $\mathrm{Ca}$. L. asiaticus'-infected periwinkle cuttings for evaluation of anti-Liberibacter compounds and demonstrate its value in testing two chemical compounds. 


\section{MATERIALS AND METHODS}

'Ca. L. asiaticus'-infected periwinkle. Periwinkle (Catharanthus roseus) plants (cultivars cv. Caribbean Lavender or Pacifica Pure White) were grown from seed and were placed adjacent to 'Candidatus L. asiaticus'-infected lemon trees (Citrus limonium) on which dodder (Cuscuta pentagona) was already well established. A young dodder shoot connected to the citrus was draped over the periwinkle plants and, subsequently, became attached to the periwinkle stems. After 1 to 3 months, periwinkle plants showing HLB-like symptoms (Fig. 1) were detached from the dodder and infections were confirmed by PCR using 'Candidatus L. asiaticus'-specific primers (26). 'Ca. L. asiaticus'-infected periwinkle plants were propagated by graft transmission. Newly expanded branches of ' $\mathrm{Ca}$. L. asiaticus'-infected periwinkle were grafted on to ' $\mathrm{Ca}$. L. asiaticus'-free periwinkle plants. Transmission was confirmed via PCR using ' $C a$. L. asiaticus'-specific primer sets and the infected periwinkle plants were maintained in the greenhouse for further studies.

Regeneration of periwinkle cuttings. The parental periwinkle plants were watered $\approx 1 \mathrm{~h}$ before the cuttings were taken. Stem cuttings of $\approx 2$ to $3 \mathrm{~cm}$ in length that contained at least two leaves were collected from ' $C a$. L. asiaticus'-free and ' $C a$. L. asiaticus'infected periwinkle plants during the early morning or late afternoon. In addition to the visual determination of ' $\mathrm{Ca}$. L. asiaticus'-infected symptoms, each cutting was confirmed as ' $\mathrm{Ca}$. L. asiaticus' positive or ' $C a$. L. asiaticus' negative by PCR using primer set OI1/OI2c (26), nested PCR with primer sets OI1/OI2c and CGO3f/CGO5r (47), and quantitative real-time (q)PCR with primer set HLBas/HLBr/HLBp (28). In this study, the cuttings were classified into three groups: (i) severe HLB-like symptoms with cycle threshold $(\mathrm{Ct})$ values $<26$, (ii) mild HLB-like symptoms with $\mathrm{Ct}$ values of 26 to 35.9 , and (iii) no symptoms with $\mathrm{Ct}$ values $\geq 36$.

The basal end of each cutting was dipped in Rootone rooting powder (GardenTech., Rolling Meadows, IL). The treated cuttings were planted in vermiculite (grade no. 3; Sigma-Aldrich, St. Louis), kept at $25^{\circ} \mathrm{C} \pm 2{ }^{\circ} \mathrm{C}$ under shade, and misted daily in the greenhouse. After 2 months, the plants regenerated from cuttings were harvested and analyzed to determine the regeneration rate (percent), biomass (grams of fresh weight), shoot length (in centimeters), and branch number. The regenerated plants were also tested for the presence of the ' $C a$. L. asiaticus' bacteria by PCR.

Optimization of regeneration factors for ' $\mathrm{Ca}$. L. asiaticus'infected cuttings. The effect of soil composition (SC) and plant growth regulators (PGRs) on the regeneration of mildly ' $\mathrm{Ca}$. L. asiaticus'-infected cuttings were evaluated in the plant pot carrytrays (50 wells) (Plastic Flowerpots, Lake Worth, FL) under greenhouse conditions. The factors were arranged in a split-plot design with three replicates. SC was the whole plot factor, with three levels composed of different ratios of vermiculite to soil: (i) $100 \%$ vermiculite, (ii) $50 \%$ vermiculite to $50 \%$ soil (vol/vol), and (iii) $100 \%$ soil, while the following PGRs were considered as the subplot treatments: (i) NAA at $5 \mu \mathrm{g} / \mathrm{ml}$, (ii) IBA at $5 \mu \mathrm{g} / \mathrm{ml}$, and (iii) a water-treated control. All cuttings were treated and planted as above except that they were fertilized with one-half strength Murashige and Tucker (MT) nutrient medium (34). Data were analyzed as a generalized linear mixed model using the SAS procedure GLIMMIX. The whole plot and subplot factors were treated as fixed effects and replication and its interaction with the whole plot factor as random effects. Differences among treatment levels were determined with the LINES option of the LSMEANS statement.

To optimize the regeneration system, the effects of NAA, IBA, and nutrient medium composition on the regeneration rate of ' $\mathrm{Ca}$. L. asiaticus'-infected and ' $C a$. L. asiaticus'-free cuttings were evaluated using a uniform experimental design (UD) $(17,45)$. Specialized software has been developed to assist in the design of the so-called UD table, which assigns the various factor levels to a specific experimental run (Data Processing System, DPS V3.01; Refine Information Tech Co. Ltd., Beijing). A UD table $\mathrm{U}_{10}\left(2^{5}\right.$ by $2^{2}$ ) was designed to assess the effects of the four factors at different levels in 10 runs: NAA $\left(x_{1}\right)$ and IBA $\left(x_{2}\right)$ at five levels, cuttings $\left(x_{3}\right)$ at two levels (i.e., ' $C a$. L. asiaticus'-infected or not), and nutrient medium composition $\left(x_{4}\right)$ at two levels (i.e., one-half strength of Murashige and Skoog medium [MS] [33] or MT medium) (Table 1). Each run was conducted on 15 cuttings with three replicates. After 2 months, the regenerated plants were harvested from the vermiculite and washed carefully with running water to remove the vermiculite around the roots. The biomass (grams of fresh weight), shoot length (in centimeters), and branch number were measured and recorded as above.

TABLE 1. Factors and levels on the uniform design of experiments with mixtures of $\mathrm{U}_{10}\left(2^{5}\right.$ by $\left.2^{2}\right)$

\begin{tabular}{lclllll}
\hline & & \multicolumn{5}{c}{ Factor level $^{\mathrm{z}}$} \\
\cline { 3 - 7 } Factor $^{\mathrm{y}}$ & Symbol & \multicolumn{1}{c}{0} & 1 & 2 & 3 & 4 \\
\hline NAA $(\mu \mathrm{g} / \mathrm{ml})$ & $x_{1}$ & 0 & 2 & 4 & 6 & 8 \\
IBA $(\mu \mathrm{g} / \mathrm{ml})$ & $x_{2}$ & 0 & 2 & 4 & 6 & 8 \\
Cultural media & $x_{3}$ & MS & MT & $\ldots$ & $\ldots$ & $\ldots$ \\
Cuttings & $x_{4}$ & Free & Mild & $\ldots$ & $\ldots$ & $\ldots$ \\
\hline
\end{tabular}

${ }^{\text {y }}$ NAA $=$ naphthalene acetic acid and IBA = indole-3-butyric acid.

${ }^{\mathrm{z}}$ MS = half-strength Murashige and Skoog basal salt mixture (1962); MT = half-strength Murashige and Tucker (1969) mixture: MS basal salt mixture supplemented with glycine at $2.0 \mathrm{mg} / \mathrm{ml}$, myo-inositol at $100 \mu \mathrm{g} / \mathrm{ml}$, nicotinamide at $5 \mu \mathrm{g} / \mathrm{ml}$, pyridoxine $\mathrm{HCl}$ at $10 \mu \mathrm{g} / \mathrm{ml}$, and thiamine $\mathrm{HCl}$ at $10 \mu \mathrm{g} / \mathrm{ml}$; Free $=$ 'Candidatus Liberibacter asiaticus'-free cuttings with cycle threshold $(\mathrm{Ct})$ value $>36.0$ as determined by quantitative real-time polymerase chain reaction (qPCR); and Mild = mildly ' $\mathrm{Ca}$. L. asiaticus'-infected cuttings with $\mathrm{Ct}$ value of 26.0 to 35.9 as determined by qPCR.
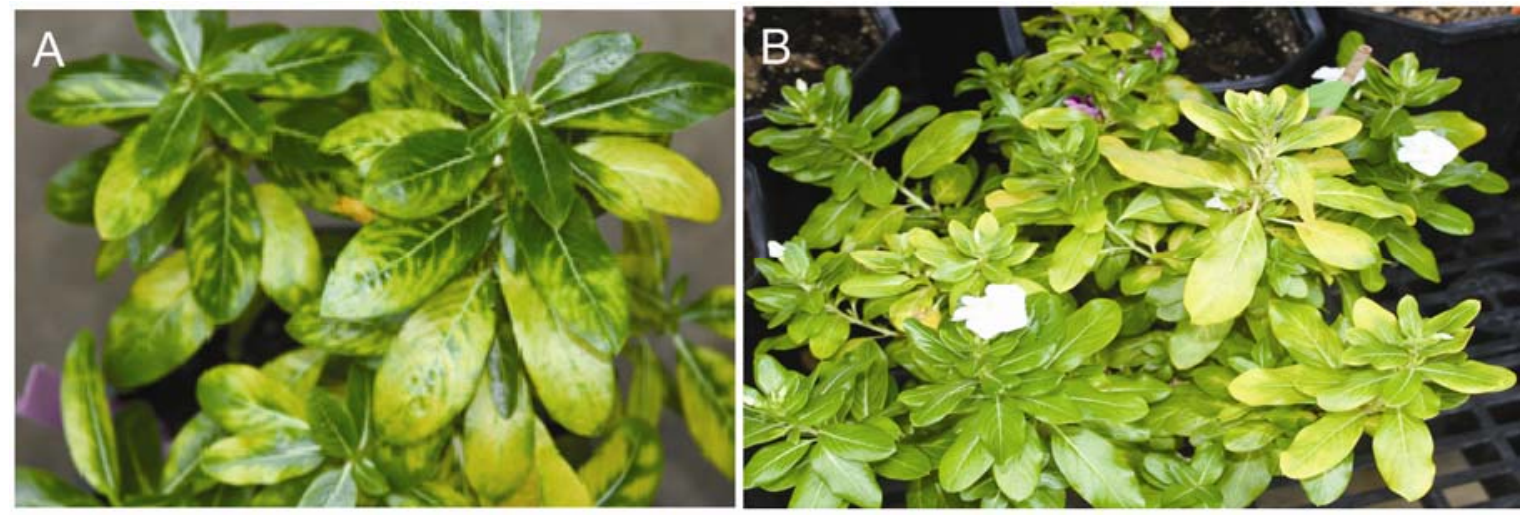

Fig. 1. 'Candidatus Liberibacter asiaticus'-infected periwinkle plants. A, Periwinkle with severe citrus huanglongbing (HLB)-like symptoms and a low cycle threshold $(\mathrm{Ct})$ value via quantitative real-time polymerase chain reaction and $\mathbf{B}$, periwinkle with mild HLB-like symptoms and a high Ct value. 
Partial least squares (PLS) regression was used to analyze the results of each of the response variables of the UD trial $(16,46)$. The following model was fit to the data:

$$
y=\beta_{0}+\sum_{i=1}^{m} \beta_{i} x_{i}+\sum_{i=1}^{m} \beta_{i i} x^{2}{ }_{i}+\sum_{i\langle j} \beta_{i j} x_{i} x_{j}+e
$$

where $y$ is the response variable (i.e., biomass, shoot length, or branch number), $\beta_{0}, \beta_{i}, \beta_{i i}$, and $\beta_{i j}$ are the regression coefficients, $x_{\mathrm{i}}$ and $x_{\mathrm{j}}$ are the regeneration factors, $m$ is an index variable ranging from 1 to 4 , and $e$ is the random error. Model performance was evaluated by comparing the measured and the predicted values of shoot length, biomass, and branch number of regenerated plants. The coefficient of determination of the model $\left(R^{2}\right)$ and the predicted residual sum of squares (PRESS) were calculated to determine whether or not there was a good fit of the predicted model.

Effects of chemical compounds on eliminating or suppressing ' $\boldsymbol{C} \boldsymbol{a}$. L. asiaticus' bacterium. Two compounds were evaluated for their potential to eliminate or suppress ' $\mathrm{Ca}$. L. asiaticus' bacterium in the greenhouse trials: the antibiotic penicillin $G$ sodium at concentrations of 25 or $50 \mu \mathrm{g} / \mathrm{ml}$ (1,690 units/mg) (Sigma-Aldrich) and a $20 \%$ solution of the biocide agent 2,2-dibromo-3-nitrilopropionamide (DBNPA) at concentrations of 100 or $200 \mu \mathrm{l} /$ liter (Dow Chemical, Midland, MI). Tap water was used as a control. The stems of severely ' $\mathrm{Ca}$. L. asiaticus'-infected cuttings were individually soaked in the DBNPA or penicillin G sodium solutions for $4 \mathrm{~h}$ and then planted in $100 \%$ vermiculite using the optimized regeneration systems described above. The cuttings were further treated with the solutions at 7 and 14 days post transplanting. Each experiment was repeated twice with 15 cuttings per treatment. The efficacy of the DBNPA was evaluated based on the percentage of surviving ' $\mathrm{Ca}$. L. asiaticus'-infected cuttings and the survival of ' $\mathrm{Ca}$. L. asiaticus' bacteria in the regenerated plants by PCR.

PCR test of ' $\boldsymbol{C a}$. L. asiaticus' bacterium. Each leaf sample was rinsed three times with sterile water. Midribs were separated from the leaf samples and cut into pieces of 1.0 to $2.0 \mathrm{~mm}$. DNA was extracted from $0.1 \mathrm{~g}$ of tissue (fresh weight) of leaf midribs using Qiagen's DNeasy Plant Mini Kit (Qiagen, Valencia, CA) according to the manufacturer's protocol. PCR was performed as described by Jagoueix et al. (26) using the OI1/OI2c primer set in a $20-\mu \mathrm{l}$ reaction containing $10 \mu \mathrm{l}$ of $2 \times$ Premix D (Epicenter Technologies, Madison, WI), $0.5 \mu \mathrm{l}$ of a $10-\mu \mathrm{M}$ dilution for each primer, $2 \mu \mathrm{l}$ of DNA solution, and $1.5 \mathrm{U}$ of DNA polymerase (BioLabs, Ipswich, MA). Amplification was performed as follows: 1 cycle of $3 \mathrm{~min}$ at $94^{\circ} \mathrm{C} ; 40$ cycles of $45 \mathrm{~s}$ at $94^{\circ} \mathrm{C}, 45 \mathrm{~s}$ at $64^{\circ} \mathrm{C}$ and $1 \mathrm{~min}$ at $72^{\circ} \mathrm{C}$; followed by a final extension at $72^{\circ} \mathrm{C}$ for $10 \mathrm{~min}$. For nested PCR, each $20 \mu \mathrm{l}$ of reaction mixture contained $10 \mu \mathrm{l}$ of $2 \times$ Premix D, $0.5 \mu \mathrm{l}$ of a $10-\mu \mathrm{M}$ dilution of primers CGO3f/CGO5r (47), $1 \mu \mathrm{l}$ of PCR product from the first run as described above, and $1.5 \mathrm{U}$ of Taq DNA polymerase. Amplification was performed as follows: 1 cycle of $3 \mathrm{~min}$ at $94^{\circ} \mathrm{C} ; 34$ cycles of $30 \mathrm{~s}$ at $94^{\circ} \mathrm{C}, 30 \mathrm{~s}$ at $53^{\circ} \mathrm{C}$, and $1 \mathrm{~min}$ at $72^{\circ} \mathrm{C}$; followed by a final extension at $72^{\circ} \mathrm{C}$ for $7 \mathrm{~min}$. PCR products were separated by electrophoresis on $1.0 \%$ agarose gels, and visualized by ethidium bromide staining. qPCR was performed with the primers and probes (HLBas/HLBr/HLBp) (28) for ' $\mathrm{Ca}$. L. asiaticus' using ABI PRISM 7500 Sequence detection system (Applied Biosystems, Foster City, CA) in a $20-\mu$ reaction volume consisting of the following reagents: $300 \mathrm{nM}$ (each) target primer (HLBas and HLBr), $150 \mathrm{nM}$ target probe (HLBp), and $1 \times$ TaqMan qPCR Mix (Applied Biosystems). The amplification protocol was $95^{\circ} \mathrm{C}$ for $20 \mathrm{~s}$ followed by 40 cycles at $95^{\circ} \mathrm{C}$ for $3 \mathrm{~s}$ and $60^{\circ} \mathrm{C}$ for $30 \mathrm{~s}$. All reactions were performed in triplicate and each run contained one negative and one positive control. The data were analyzed using the 7500 Fast Real-Time PCR System with SDS software.

\section{RESULTS}

Dodder and graft transmission of ' $\mathrm{Ca}$. L. asiaticus' to periwinkle plants. HLB-like symptoms appeared on periwinkle plants 2 to 3 months after inoculation by dodder transmission. On periwinkle plants (cv. Pacifica Pure White), HLB-like symptoms were characterized with an initial vein yellowing that progressively expanded into whole-leaf yellowing (Fig. 1A). However, mild HLB-like symptoms could be characterized by a similar blotchy mottle on leaves and yellowing of shoots (Fig. 1B) and were observed on certain ' $\mathrm{Ca}$. L. asiaticus'-infected periwinkle plants. When an aggressive ' $C a$. L. asiaticus' bacterial source was used, the earliest appearance of HLB-like symptoms on the grafttransmitted periwinkle plants was 3 weeks postinoculation. The ' $C a$. L. asiaticus' bacterial titer in ' $C a$. L. asiaticus'-infected periwinkle plants varied greatly, with $\mathrm{Ct}$ values of 19.0 to 35.9 as determined by qPCR. Periwinkle plants that were severely affected by the disease $(\mathrm{Ct}$ value $<26.0)$ often died within 6 months postinfection, whereas the mild type $(\mathrm{Ct}$ value $>28.0)$ normally survived $>6$ months. In general, the more severe the HLB-like symptoms were, the higher the titer of the ' $C a$. L. asiaticus' bacterium and the more quickly the ' $C a$. L. asiaticus'-infected plants died (data not shown).

Optimization of the regeneration system for ' $\boldsymbol{C a}$. L. asiaticus'-infected cuttings. There were significant effects of SC $(P=$ $0.0005)$ and PGR $(P=0.0004)$ on biomass but the interaction of these factors was not significant. Biomass was the greatest for cuttings planted in $100 \%$ vermiculite, followed by the $50 / 50$ mixture of vermiculite and soil, and then soil alone (Table 2). The addition of the NAA at $5 \mu \mathrm{g} / \mathrm{ml}$ produced significantly larger cuttings than IBA or the untreated cuttings, whereas the latter two were not significantly different from each other (Table 2 ). There were significant effects of PGR $(P<0.0001)$ on the regeneration rate but soil composition did not significantly affect regeneration. Their interaction was significant $(P=0.0120)$ but only for differences within the main effect of PGR because evaluation of the interaction term did not reveal any information of significance. The regeneration rate of the cuttings was $100 \%$ with the

TABLE 2. Effects of soil compositions (SCs) and plant growth regulators (PGRs) on the mildly 'Candidatus Liberibacter asiaticus'-infected periwinkle cuttings revealed by biomass (grams of fresh weight) and regeneration rate (percent) 2 months after the mildly ' $\mathrm{Ca}$. L. asiaticus'-infected cuttings were transplanted ${ }^{z}$

\begin{tabular}{lcc}
\hline Treatments & Biomass $(\mathrm{g})$ & Regeneration rate $(\%)$ \\
\hline SCs & & \\
$100 \%$ vermiculite & $13.18 \pm 2.67 \mathrm{a}$ & $88.9 \pm 14.40 \mathrm{a}$ \\
$50 \%$ vermiculite $+50 \%$ soil $(\mathrm{v} / \mathrm{v})$ & $10.02 \pm 4.60 \mathrm{ab}$ & $91.7 \pm 17.70 \mathrm{a}$ \\
$100 \%$ soil & $7.68 \pm 4.10 \mathrm{~b}$ & $91.7 \pm 17.70 \mathrm{a}$ \\
PGRs & $9.96 \pm 4.96 \mathrm{~b}$ & $94.5 \pm 11.77 \mathrm{a}$ \\
Indole-3-butyric acid at $5 \mu \mathrm{g} / \mathrm{ml}$ & $13.58 \pm 1.92 \mathrm{a}$ & $100 \pm 0 \mathrm{a}$ \\
Naphthalene acetic acid at $5 \mu \mathrm{g} / \mathrm{ml}$ & $7.74 \pm 3.45 \mathrm{~b}$ & $77.8 \pm 20.0 \mathrm{~b}$ \\
CK (water control) & & \\
\hline
\end{tabular}

${ }^{\mathrm{z}}$ Data were analyzed as a generalized linear mixed model using the SAS procedure GLIMMIX. The whole-plot and subplot factors were treated as fixed effects, and replication and its interaction with the whole-plot factor as random effects. Differences among treatment levels were determined with the LINES option of the LSMEANS statement. Means among treatment levels followed by a different letter are significantly different $(P<0.05)$. 
addition of NAA at $5 \mu \mathrm{g} / \mathrm{ml}$, followed by $94.5 \%$ with the addition of IBA at $5 \mu \mathrm{g} / \mathrm{ml}$ and only $77.8 \%$ for the water control. The PGRs were not significantly different from each other but were both significantly different from the control (Table 2). The regeneration rates were 88.9 to $91.7 \%$ among SC types and were statistically equivalent.

The following models were developed for the prediction of shoot length, biomass, and branch number.

$$
\begin{gathered}
\text { Shoot length }=5.75+1.27 x_{1}+5.71 x_{2}+3.27 x_{3}+ \\
2.28 x_{4}-0.53 x_{1}^{2}-1.44 x_{2}^{2}+0.01 x_{1} x_{2}-1.20 x_{1} x_{3}+ \\
0.64 x_{1} x_{4}-1.48 x_{2} x_{3}-0.47 x_{2} x_{4}-1.07 x_{3} x_{4}
\end{gathered}
$$

Biomass $=31.86-0.79 x_{1}+6.55 x_{2}+8.09 x_{3}-14.58 x_{4}+$

$0.34 x_{1}^{2}-1.98 x_{2}^{2}-0.07 x_{1} x_{2}-3.21 x_{1} x_{3}+3.64 x_{1} x_{4}-$

$3.88 x_{2} x_{3}+0.21 x_{2} x_{4}+5.22 x_{3} x_{4}$

$$
\begin{gathered}
\text { Branch number }=3.64-0.30 x_{1}+0.83 x_{2}+1.14 x_{3}- \\
1.94 x_{4}-0.039 x_{1}^{2}-0.21 x_{2}^{2}-0.04 x_{1} x_{2}-0.20 x_{1} x_{3}+ \\
0.58 x_{1} x_{4}-0.62 x_{2} x_{3}+0.09 x_{2} x_{4}+0.08 x_{3} x_{4}
\end{gathered}
$$

where $x_{1}$ is NAA at five levels, $x_{2}$ is IBA at five levels, $x_{3}$ is cuttings at two levels of ' $C a$. L. asiaticus'-infected or not, and $x_{4}$ is nutrient composition at two level of one-half strength of MS or MT.

For each of the variables in equations 1 to 3 , the predicted values were in good agreement with the observed data according to the $R^{2}$ and PRESS statistics (Tables 3 and 4). The optimal levels of the factors in the regeneration system identified by PLS analysis were having the cuttings fertilized with half-strength MT medium supplemented with NAA at $4 \mu \mathrm{g} / \mathrm{ml}$ and IBA at $4 \mu \mathrm{g} / \mathrm{ml}$. This led to predicted outcomes of $12.66 \mathrm{~cm}$ for shoot length, $24.45 \mathrm{~g}$ for biomass, and 1.55 for branch number. The optimized system was assessed by the regeneration rates (percent) of severely ' $C a$. L. asiaticus'-infected cuttings and ' $C a$. L. asiaticus'-free cuttings compared with that of the water control (without exogenous PGRs) (Fig. 2). Using the above optimized regeneration system, the regeneration rate for severely ' $\mathrm{Ca}$. $\mathrm{L}$. asiaticus'-infected cuttings was 38.1 to $75.0 \%$ with an average of $60.6 \%$ (Fig. 2, column C), whereas $<1 \%$ (Fig. 2, column D) of plants were regenerated from severely ' $C a$. L. asiaticus'-infected cuttings treated with water alone. However, without chemical treatment, all regenerated plants from severe ' $\mathrm{Ca}$. L. asiaticus'infected cuttings grew slowly and died within 1 month post transplantation. As compared with the severely ' $C a$. L. asiaticus'infected ones, $>80 \%$ (Fig. 2, column A) of ' $\mathrm{Ca}$. L. asiaticus'-free cuttings regenerated in the optimized regeneration systems and $57.1 \%$ (Fig. 2, column B) in the control (using tap water only).

Screening of chemical compounds for eliminating or suppressing ' $\mathrm{Ca}$. L. asiaticus' bacterium using the optimized re- generation system. In all, $>60 \%$ of the severely infected cuttings treated with penicillin $\mathrm{G}$ sodium were rooted and regenerated. All plants regenerated from the ' $\mathrm{Ca}$. L. asiaticus'-infected cuttings treated with penicillin $\mathrm{G}$ sodium at $50 \mu \mathrm{g} / \mathrm{ml}$ tested negative for ' $\mathrm{Ca}$. L. asiaticus' bacterium via PCR. The ' $\mathrm{Ca}$. L. asiaticus' bacterium was undetectable in these regenerated plants (Table 5). When treated with penicillin $\mathrm{G}$ sodium at $25 \mu \mathrm{g} / \mathrm{ml}$, the regenerated plants tested positive only by nested PCR or qPCR, with high $\mathrm{Ct}$ values of 32.84 to 36.57 (Table 5), indicating a low titer of ' $\mathrm{Ca}$. L. asiaticus' bacterium. The regenerated control plants treated with water tested positive by PCR and $\mathrm{qPCR}$, with low $\mathrm{Ct}$ values $<26.0$, indicating that the bacterial titers were at least 100 fold higher than those in the penicillin-treated periwinkle plants. When the severely ' $C a$. L. asiaticus'-infected cuttings were treated with DBNPA at 200 or $100 \mu \mathrm{l} /$ liter, the regeneration rate was $>40 \%$, of which only $16.7 \%$ (one PCR-positive out of six

TABLE 4. Coefficient of determination $\left(R^{2}\right)$, predicted residual sum of squares (PRESS) and optimally predicted values from the models for shoot length (in centimeters), fresh biomass (grams of fresh weight), and branch number by partial least squares regression analysis

\begin{tabular}{lccc}
\hline Measurements & $R^{2}$ & PRESS & Optimally predicted value \\
\hline Shoot length & 0.870 & 11.036 & 12.66 \\
Fresh biomass & 0.953 & 10.362 & 24.45 \\
Branch number & 0.944 & 10.776 & 1.55 \\
\hline
\end{tabular}

${ }^{\mathrm{z}}$ Optimally predicted values were calculated from the models using the optimized regeneration factors.

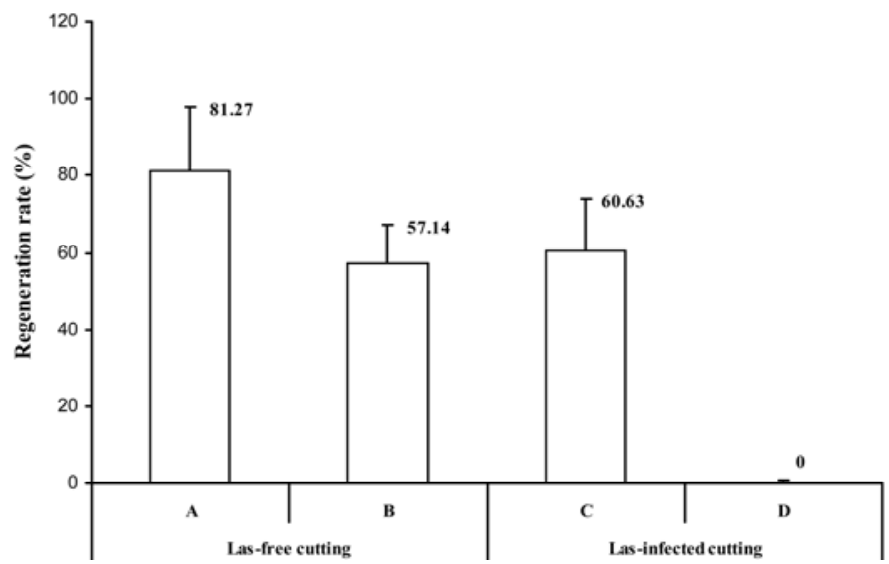

Fig. 2. Regeneration rates (\%) from the 'Candidatus Liberibacter asiaticus'

\begin{tabular}{|c|c|c|c|c|c|c|c|c|c|c|}
\hline \multirow[b]{2}{*}{ Runs } & \multicolumn{4}{|c|}{ Factor $(\text { level })^{\mathrm{z}}$} & \multicolumn{2}{|c|}{ Shoot length $(\mathrm{cm})$} & \multicolumn{2}{|c|}{ Biomass (g) } & \multicolumn{2}{|c|}{ No. of branches } \\
\hline & $x_{1}$ & $x_{2}$ & $x_{3}$ & $x_{4}$ & Obs & Pred & Obs & Pred & Obs & Pred \\
\hline$\overline{\mathrm{R}_{1}}$ & 4 & 3 & 1 & 1 & $3.6 \pm 0.12$ & 4.3 & $10.29 \pm 0.35$ & 10.75 & $1 \pm 0.1$ & 1.2 \\
\hline $\mathrm{R}_{2}$ & 3 & 4 & 1 & 0 & 0 & 0.2 & 0 & -1.4 & 0 & -0.3 \\
\hline $\mathrm{R}_{4}$ & 1 & 4 & 0 & 1 & $6.3 \pm 0.14$ & 8.5 & $11.48 \pm 1.32$ & 23.31 & $2 \pm 0.1$ & 2.7 \\
\hline $\mathrm{R}_{5}$ & 3 & 0 & 0 & 1 & $6.3 \pm 0.09$ & 6.3 & $19.23 \pm 1.09$ & 16.78 & $1.8 \pm 0.1$ & 1.9 \\
\hline $\mathrm{R}_{6}$ & 2 & 2 & 0 & 1 & $17.7 \pm 1.24$ & 9 & $28.37 \pm 3.21$ & 24.56 & $3.5 \pm 0.2$ & 2.9 \\
\hline $\mathrm{R}_{10}$ & 2 & 2 & 1 & 0 & $7.5 \pm 0.78$ & 8 & $19.84 \pm 1.08$ & 21.83 & $2.5 \pm 0.1$ & 2.5 \\
\hline
\end{tabular}
(Las)-infected (columns $\mathrm{C}$ and $\mathrm{D}$ ) and the ' $\mathrm{Ca}$. L. asiaticus' (Las)-free (columns A and B) cuttings using the optimized regeneration system (columns $\mathrm{C}$ and $\mathrm{A}$ ) compared with the tap water as control (columns D and B).

TABLE 3. Comparison of the measured values of shoot length (in centimeters), fresh biomass (grams of fresh weight), and branch number and their predicted values calculated by partial least squares regression from uniform experimental design of the four factors with mixtures of $\mathrm{U}_{10}\left(2^{5} \text { by } 2^{2}\right)^{\mathrm{y}}$

y Experimental runs and treatment combinations were optimized using uniform design with mixture levels by DPS software package. Each experimental run was repeated three times and at least 10 regenerated plants from cuttings were investigated in each repetition, except for experimental run $R_{2}$. Data are the mean value of the three replicates. Regenerated plants were analyzed for the biomass, length of major shoots, and branch number 2 months after the mildly 'Candidatus Liberibacter asiaticus'-infected cuttings were planted. Obs $=$ measured values and Pred $=$ predicted values from mathematical models.

${ }^{\mathrm{z}}$ Levels of regeneration factors listed in Table 1. 
regenerated plants at $200 \mu \mathrm{l} /$ liter) and $22.3 \%$ (two PCR-positive out of nine regenerated plants at $100 \mu \mathrm{l} /$ liter) were ' $\mathrm{Ca}$. L. asiaticus' positive by PCR (Fig. 3). The efficacy for DBNPA treatment was $66.6 \%$ (for $200 \mu \mathrm{l} /$ liter) and $55.4 \%$ (for $100 \mu \mathrm{l} / \mathrm{liter}$ ) in eliminating the ' $C a$. L. asiaticus' bacterium in the regenerated plants. The plants regenerated from the severely infected cuttings without DBNPA treatment had lower $\mathrm{Ct}$ values, grew slowly, and died within 1 month posttransplantation in soil, whereas those treated with DBNPA had higher $\mathrm{Ct}$ values and grew well (Table 6; Fig. 4). Compared with the control plants, the biomass of the regenerated plants increased by $92.75 \%$ for the severely infected cuttings treated with penicillin $\mathrm{G}$ sodium at $50 \mu \mathrm{g} / \mathrm{ml}$ and by $49.9 \%$ when treated with DBNPA at $200 \mu \mathrm{l} /$ liter (Table 6). The higher regeneration rates and increased biomass in the regenerated plants from severely infected cuttings treated with penicillin $\mathrm{G}$ sodium or DBNPA indicated that these compounds eliminated or suppressed the ' $C a$. L. asiaticus' bacterium in the regenerated plants and had no adverse effects on periwinkle growth.

\section{DISCUSSION}

In this study, we developed an optimized system for quick regeneration of ' $\mathrm{Ca}$. L. asiaticus'-infected periwinkle cuttings to enable screening and evaluation of chemical compounds against the HLB bacteria. This system was then used to evaluate the abilities of penicillin $\mathrm{G}$ sodium and DBNPA to eliminate or suppress the ' $C a$. L. asiaticus' bacterium in ' $C a$. L. asiaticus'- infected periwinkle plants. To our knowledge, no techniques have been developed prior to this study to allow the efficient evaluation of the efficacy of chemical compounds for the control of the HLB bacterium, 'Ca. L. asiaticus' (14,37).

Periwinkle is a preferred host of the HLB bacteria, which allows for repeated sampling for ' $\mathrm{Ca}$. L. asiaticus'-related assay $(18,19)$. However, cuttings severely infected by HLB bacteria are very difficult to root and regenerate due to the severe affects on the phloem of host plants caused by the bacteria $(2,27)$. Factors affecting the successful regeneration of ' $\mathrm{Ca}$. L. asiaticus'-infected cuttings included, but were not limited to, the ' $\mathrm{Ca}$. L. asiaticus' bacterial titers, the degree of damage to the host parent plants, cultivation conditions, and plant hormones. Because ' $\mathrm{Ca}$. L. asiaticus' bacteria are unevenly distributed in their host plants $(40,41)$, the cuttings from the ' $C a$. L. asiaticus'-infected plants may have different titers of the bacteria.

Cultivation media and conditions are vital for the regeneration of ' $C a$. L. asiaticus'-infected periwinkle cuttings. Vermiculite is a lightweight material used for rooting, holding water well, and promoting root growth. Our results indicated that the cuttings in the vermiculite rooted better than those in soil. In addition, it was found that ' $\mathrm{Ca}$. L. asiaticus'-infected periwinkle cuttings regenerated and grew better in MT medium than in MS medium. Compared with MS medium, MT medium is supplemented with vitamins such as glycine, myo-inositol, nicotinamide, pyridoxine, and thiamine, which are required for normal growth and proper development of plants. These vitamins can alleviate the adverse

TABLE 5. Regeneration rate (\%) and quantitative real-time polymerase chain reaction (qPCR) cycle threshold $(\mathrm{Ct})$ values of the regenerated plants from the severely 'Candidatus Liberibacter asiaticus'-infected cuttings treated with penicillin $\mathrm{G}$ sodium at 25 or $50 \mu \mathrm{g} / \mathrm{ml}$ and 2,2-dibromo-3-nitrilopropionamide (DBNPA) at 100 or $200 \mu \mathrm{l} / \mathrm{liter}^{\mathrm{z}}$

\begin{tabular}{lccc}
\hline & & & Ct values \\
\cline { 3 - 4 } Chemical compounds, concentrations & Regeneration rate $(\%)$ & Caribbean Lavender & Pacifica Pure White \\
\hline Penicillin G sodium $(\mu \mathrm{g} / \mathrm{ml})$ & 50 & $20.9 \pm 3.07$ & $24.87 \pm 1.44$ \\
0 & 100 & $32.84 \pm 2.76$ & $36.57 \pm 2.59$ \\
25 & 66.7 & UD & UD \\
50 & 40 & $\ldots$ & $22.14 \pm 0.93$ \\
DBNPA $(\mu \mathrm{l} / \mathrm{liter})$ & 60 & $\ldots$ & $33.24 \pm 5.13$ \\
0 & 40 & $\ldots$ & $33.71 \pm 3.18$ \\
100 & & $\ldots$ & $\ldots$ \\
\hline
\end{tabular}

${ }^{\mathrm{z}}$ Water was used as the control, qPCR was tested 2 months after treatment, and UD = undetectable fluorescence.

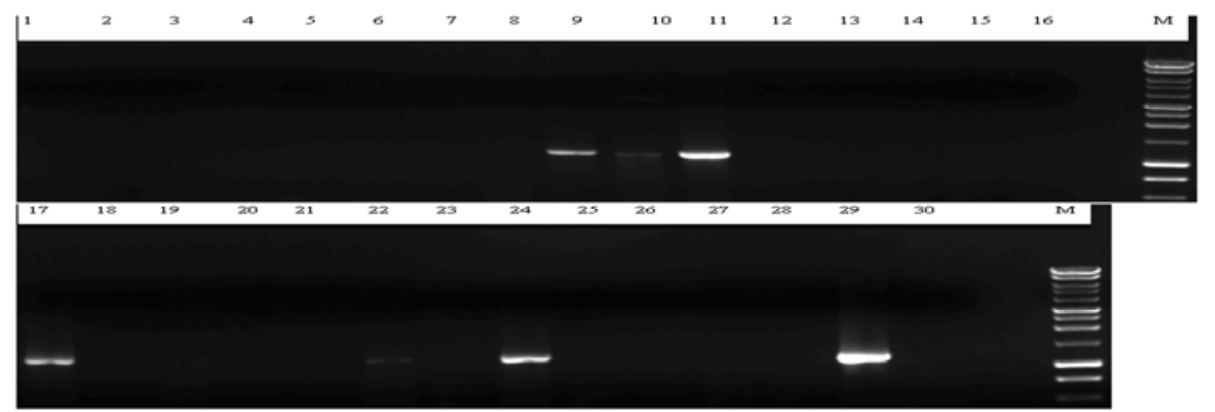

Fig. 3. Agarose gel electrophoresis of polymerase chain reaction amplicons using primer OI1/OI2c from DNA extracts of regenerated plants from the 'Candidatus Liberibacter asiaticus'-free (lanes 1 to 7) and the severely ' $\mathrm{Ca}$. L. asiaticus'-infected cuttings treated with 2,2-dibromo-3-nitrilopropionamide (DBNPA) (lanes 8 to 28) at different concentrations. Lanes 23 to 28, DBNPA treatment at $200 \mu \mathrm{l} /$ liter; lanes 14 to 22 , DBNPA treatment at $100 \mu \mathrm{l} /$ liter; and lanes 8 to 13 , control without DBNPA treatment. Lane 29, 'Ca. L. asiaticus'-infected plant as positive control. Lane 30, negative control. M, 1-kb DNA marker (Promega Corp.).

TABLE 6. Biomass (grams of fresh weight) of the regenerated plants after the severely 'Candidatus Liberibacter asiaticus'-infected cuttings were treated with penicillin G sodium and 2,2-dibromo-3-nitrilopropionamide (DBNPA) at different concentrations, 2 months after treatment ${ }^{\mathrm{z}}$

\begin{tabular}{|c|c|c|c|c|c|c|}
\hline \multirow[b]{2}{*}{ Cultivar } & \multicolumn{3}{|c|}{ Penicillin G sodium $(\mu \mathrm{g} / \mathrm{ml})$} & \multicolumn{3}{|c|}{ DBNPA $(\mu \mathrm{l} /$ liter $)$} \\
\hline & 50 & 25 & 0 & 200 & 100 & 0 \\
\hline Caribbean Lavender & $22.71 \pm 4.74$ & $13.35 \pm 6.93$ & $12.29 \pm 0.72$ & & & \\
\hline Pacifica Pure White & $8.94 \pm 1.41$ & $7.25 \pm 6.05$ & $4.13 \pm 4.29$ & $5.32 \pm 1.01$ & $3.82 \pm 1.06$ & $3.55 \pm 1.67$ \\
\hline
\end{tabular}

${ }^{\mathrm{z}}$ Each value represents mean \pm standard error of the regenerated plants. 
effect of biotic and abiotic stress by protecting the photosynthetic apparatus and acting as antioxidants $(10,22,24)$. NAA and IBA, two other PGRs, were found to be more effective in stimulating root induction than the other auxins (13). In this research, uniform design and PLS were applied to optimize the concentrations of the NAA and IBA and to develop an optimized regeneration system for screening chemical compounds and simultaneously assessing their phytotoxicity using ' $\mathrm{Ca}$. L. asiaticus'-infected periwinkle cuttings.

Compared with other orthogonal designs, a principal trait of uniform design is to compare a greater number of factors and factor levels but from fewer experiments $(17,45)$. In this study, only 10 experimental runs were conducted, representing all combinations of $128\left(2^{5}\right.$ by $\left.2^{2}\right)$ trials. PLS regression was used to analyze the data because of the interactions and strong colinearities among the regeneration factors, which traditional multiple linear regression methods cannot handle (46). Predictive models for shoot length, biomass, and branch number were developed and evaluated for fit and their predictive ability using the coefficient of determination $\left(R^{2}\right)$ and the PRESS statistic, respectively. The optimal results of the regeneration factors showed that ' $C a$. L. asiaticus'-infected cuttings can be regenerated in vermiculite fertilized with MT medium supplemented with NAA at $4 \mu \mathrm{g} / \mathrm{ml}$ and IBA at $4 \mu \mathrm{g} / \mathrm{ml}$.

The work presented here describes an efficient regeneration technique using severely ' $C a$. L. asiaticus'-infected cuttings to screen for molecules that may control citrus HLB. This optimized regeneration system, which increased the regeneration rate of severely ' $C a$. L. asiaticus'-infected cuttings by $66 \%$, was then used to rapidly screen for chemicals effective against HLB bacteria. In addition to screening many molecules quickly, it can also be used to evaluate their phytotoxicity and, thus, to increase the chance of discovering a cost-effective control for HLB bacteria. This approach has already resulted in two chemicals that will be subjected to field trials.

Penicillin $\mathrm{G}$ sodium, a water-soluble antibiotic, can be rapidly taken up systemically by plants (9). When the severely ' $\mathrm{Ca}$. L. asiaticus'-infected cuttings were treated with a penicillin G sodium solution of $50 \mu \mathrm{g} / \mathrm{ml}$, all regenerated plants were free of 'Ca. L. asiaticus' bacteria (Table 5). However, when treated with penicillin $\mathrm{G}$ sodium at $25 \mu \mathrm{g} / \mathrm{ml}$, the regenerated plants yielded $\mathrm{Ct}$ values of $\mathrm{qPCR} \geq 32.0$ and positive with nested PCR. The regenerated plants from the penicillin $\mathrm{G}$ sodium treatment grew very well, and their biomass increased by $92.75 \%$ compared with that of the control. This result demonstrated that the water-soluble penicillin $G$ sodium not only acts as a bactericide but also promotes plant growth (44). Although the application of penicillin on crops has not been approved by the Environmental Protection Agency (EPA), the effectiveness of penicillin for control of ' $\mathrm{Ca}$. L. asiaticus' bacterium and its ability to promote plant growth may merit further research and regulatory consideration.

DBNPA, a fast-acting and broad-spectrum biocide, has been widely used in industrial water systems (7). However, there is no report of the application of DBNPA to control plant disease. DBNPA's use as a pesticide is regulated under the Federal Insecticide, Fungicide, and Rodenticide Act (EPA 738-R-94-026, 1994). The percentage of ' $C a$. L. asiaticus'-positive plants and their bacterial titer were significantly reduced when the regenerated plants from severely ' $\mathrm{Ca}$. L. asiaticus'-infected cuttings were treated with DBNPA (Table 5; Fig. 3). It is worth noting that, following DBNPA treatment, the plants remaining ' $\mathrm{Ca}$. L. asiaticus' positive grew more slowly than those in which ' $\mathrm{Ca}$. L. asiaticus' was eliminated (Fig. 4).

There are other examples of chemically managing bacterial disease in perennial fruit, such as fire blight (43). Although the epidemiology of fire blight and citrus HLB are different, treatment with an antibiotic has been used as part of the control strategy for this disease of pome fruit for many years (39). The compounds found in this article may ultimately find use in field control of citrus HLB or may be used to rescue ' $\mathrm{Ca}$. L. asiaticus'infected germplasm (15), though considerable research will be necessary to justify commercial use and associated pesticide labeling. A new Liberibacter species, 'Ca. L. solanacearum', has recently been associated with the emerging zebra chip disease of potato in the United States and tomato in New Zealand $(1,29)$, and is closely related to ' $\mathrm{Ca}$. L. asiaticus' bacterium (23). Therefore, the effective chemical compounds revealed in this study may also be used for the control of zebra chip disease of potato and tomato.

\section{ACKNOWLEDGMENTS}

We thank C. Vahling for critical review on the manuscript. This research was supported by grants from the Florida Citrus Production Research Advisory Council (FCPRAC).

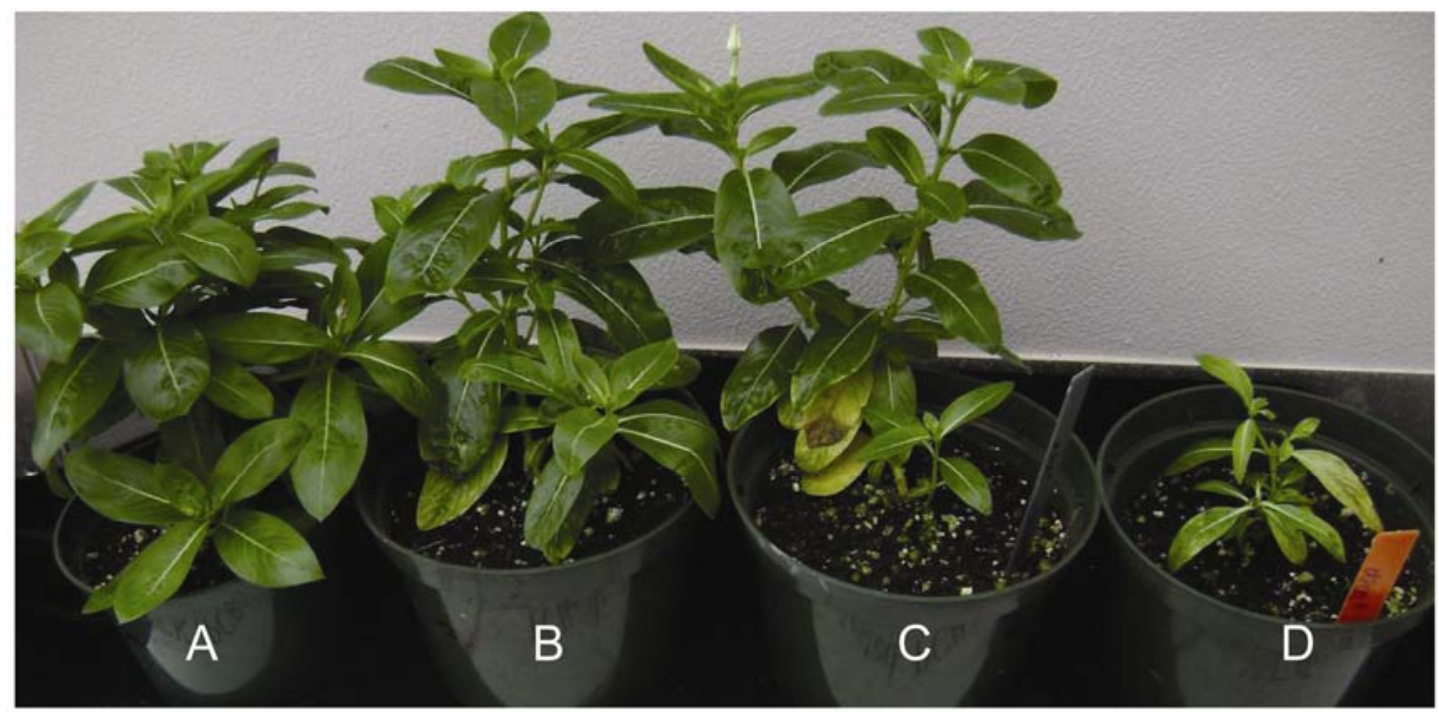

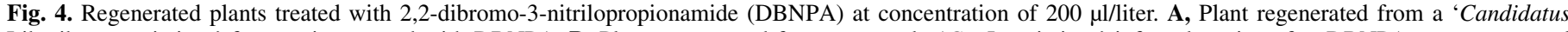

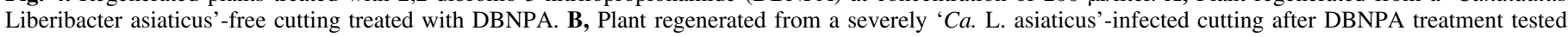

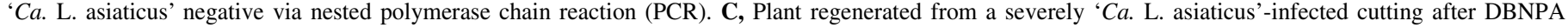

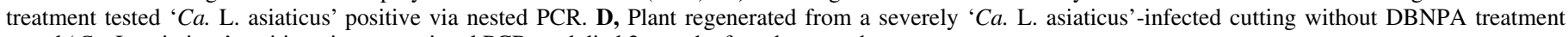
tested ' $\mathrm{Ca}$. L. asiaticus' positive via conventional PCR, and died 2 month after photograph. 


\section{LITERATURE CITED}

1. Abad, J. A., Bandla, M., French-Monar, R. D., Liefting, L. W., and Clover, G. R. G. 2009. First report of the detection of 'Candidatus Liberibacter' species in zebra chip disease-infected potato plants in the United States. Plant Dis. 93:108-109.

2. Albrecht, U., and Bowman, K. D. 2008. Gene expression in Citrus sinensis (L.) Osbeck following infection with the bacterial pathogen 'Candidatus Liberibacter asiaticus' causing huanglongbing in Florida. Plant Sci. 175:291-306.

3. Aubert, B., and Bové, J. M. 1980. Effect of penicillin or tetracycline injections of citrus trees affected by conditions in Reunion Island. Pages 103-108 in: 8th Conf. Int. Organ. Citrus Virol. B. Calavan, S. M. Garnsey, and L. W. Timmer, eds. IOCV, Riverside, CA.

4. Aubert, B., Bové, J. M., and Etienne, J. 1980. Control of greening disease of citrus in the Islands of Reunion-results and outlook. Fruits 35:605-624.

5. Aubert, B., Garnier, M., Guillaumin, D., Herbagyandono, B., Setiobudi, L., and Nurhadi, F. 1985. Greening, a serious threat for the citrus productions of the Indonesian Archipelago-future prospects of integrated control. Fruits 40:549-563.

6. Aubert, B., and Quilici, S. 1984. Biological control of psyllid vectors of greening disease in Reunion Island. Pages 118-123 in: 9th Conf. Int. Organ. Citrus Virol. S. M. Garnsey, L. W. Timmer, and J. A. Dodds, eds. IOCV, Riverside, CA.

7. Blanchard, F. A., Gonsior, S. J., and Hopkins, D. L. 1987. 2,2-Dibromo3-Nitrilopropionamide (DBNPA) chemical degradation in natural waters - experimental evaluation and modeling of competitive pathways. Water Res. 21:801-807.

8. Bové, J. M., Bonnet, P., Garnier, M., and Aubert, B. 1980. Penicillin and tetracycline treatments of greening disease affected citrus plants in the greenhouse and the bacterial nature of the prokaryote associated with greening. Pages 91-97 in: 8th Conf. Int. Organ. Citrus Virol. B. Calavan, S. M. Garnsey, and L. W. Timmer, eds. IOCV, Riverside, CA.

9. Brian, P. W., Wright, J. M., Stubbs, J., and Way, A. M. 1951. Uptake of antibiotic metabolites of soil microorganisms by plants. Nature 167:347-349.

10. Chen, H., and Xiong, L. M. 2005. Pyridoxine is required for postembryonic root development and tolerance to osmotic and oxidative stresses. Plant J. 44:396-408.

11. Coletta-Filho, H. D., Takita, M. A., Targon, M. L. P. N., and Machado, M. A. 2005. Analysis of $16 \mathrm{~S}$ rDNA sequences from citrus huanglongbing bacteria reveal a different ' $\mathrm{Ca}$. Liberibacter' strain associated with citrus disease in São Paulo. Plant Dis. 89:848-852.

12. Coletta-Filho, H. D., Targon, M., Takita, M. A., de Negri, J. D., Pompeu, J., Machado, M. A., and Muller, G. W. 2004. First report of the causal agent of huanglongbing ('Candidatus Liberibacter asiaticus') in Brazil. Plant Dis. 88:1382-1382.

13. Crkovic Perica, M. 2008. Auxin-treatment induces recovery of phytoplasma-infected periwinkle. J. Appl. Microbiol. 105:1826-1834.

14. Davis, M. J., Mondal, S. N., Chen, H. Q., Rogers, M. E., and BrIansky, R. H. 2008. Co-cultivation of 'Candidatus Liberibacter asiaticus' with actinobacteria from citrus with huanglongbing. Plant Dis. 92:1547-1550.

15. Ding, F., Jin, S. X., Hong, N., Zhong, Y., Cao, Q., Yi, G. J., and Wang, G. P., 2008. Vitrification-cryopreservation, an efficient method for eliminating 'Candidatus Liberobacter asiaticus', the citrus huanglongbing pathogen, from in vitro adult shoot tips. Plant Cell Rep. 27:241-250.

16. Eriksson, L., Hermens, J. L. M., Johansson, E., Verhaar, H. J. M., and Wold, S. 1995. Multivariate analysis of aquatic toxicity data with PLS. Aquat. Sci. 57:217-241.

17. Fang, K. T., Lin, D. K. J., Winker, P., and Zhang, Y. 2000. Uniform design: theory and application. Technometrics 42:237-248.

18. Garnier, M., and Bové, J. M. 1983. Transmission of the organism associated with citrus greening disease from sweet orange to periwinkle by dodder. Phytopathology 73:1358-1363.

19. Garnier, M., Danel, N., and Bové, J. M. 1984. Transmission of citrus greening disease from sweet orange to periwinkle (Vinca-Rosea) by dodder (Cuscuta campestris) and proof of the bacterial nature of the organism. Yale J. Biol. Med. 57:904-904.

20. Gottwald, T. R., da Graca, J. V., and Bassanezi, R. B. 2007. Citrus huanglongbing: the pathogen and its impact. Online. Plant Health Progress doi:10.1094/PHP-2007-0906-01.

21. Halbert, S. E., and Manjunath, K. L. 2004. Asian citrus psyllids (Sternorrhyncha: Psyllidae) and greening disease of citrus: a literature review and assessment of risk in Florida. Fla. Entomol. 87:330-353.

22. Hamada, A. M., and Khulaef, E. M. 2000. Stimulative effects of ascorbic acid, thiamin or pyridoxine on Vicia faba growth and some related metabolic activities. Pak. J. Biol. Sci. 3:1330-1332.

23. Hansen, A. K., Trumble, J. T., Stouthamer, R., and Paine, T. D. 2008. A new huanglongbing species, 'Candidatus Liberibacter psyllaurous', found to infect tomato and potato, is vectored by the psyllid Bactericera cockerelli (Sulc). Appl. Environ. Microbiol. 74:5862-5865.
24. Hassanein, R. A., Bassuony, F. M., Baraka, D. M., and Khalil, R. R. 2009. Physiological effects of nicotinamide and ascrobic acid on Zea mays plant grown under salinity stress. I. Changes in growth, some relevant metabolic activities and oxidative defense systems. Res. J. Agric. Biol. Sci. 5:72-81.

25. Jagoueix, S., Bové, J. M., and Garnier, M. 1994. The phloem-limited bacterium of greening disease of citrus is a member of the alpha subdivision of the Proteobacteria. Int. J. Syst. Bacteriol. 44:379-386.

26. Jagoueix, S., Bové, J. M., and Garnier, M. 1996. PCR detection of the two 'Candidatus Liberobacter' species associated with greening disease of citrus. Mol. Cell Probes 10:43-50.

27. Kim, J. S., Sagaram, U. S., Burns, J. K., Li, J. L., and Wang, N. 2009. Response of sweet orange (Citrus sinensis) to 'Candidatus Liberibacter asiaticus' infection: microscopy and microarray analyses. Phytopathology 99:50-57.

28. Li, W. B., Hartung, J. S., and Levy, L. 2006. Quantitative real-time PCR for detection and identification of 'Candidatus Liberibacter' species associated with citrus huanglongbing. J. Microbiol. Methods 66:104-115.

29. Liefting, L. W., Sutherland, P. W., Ward, L. I., Paice, K. L., Weir, B. S., and Clover, G. R. G. 2009. A new 'Candidatus Liberibacter' species associated with diseases of Solanaceous crops. Plant Dis. 93:208-214.

30. Lopes, S. A., and Frare G. F. 2008. Graft transmission and cultivar reaction of citrus to 'Candidatus Liberibacter americanus'. Plant Dis. 92:21-24.

31. Lopes, S. A., Frare, G. F., Bertolini, E., Cambra, M., Fernandes, N. G., Ayres, A. J., Marin, D. R., and Bove, J. M. 2009. Liberibacters associated with citrus huanglongbing in Brazil: 'Candidatus Liberibacter asiaticus' is heat tolerant, 'Ca. L. americanus' is heat sensitive. Plant Dis. 93:257-262.

32. Lopes, S. A., Frare, G. F., Yamamoto, P. T., Ayres, A. J., and Barbosa, J. C. 2007. Ineffectiveness of pruning to control citrus huanglongbing caused by 'Candidatus Liberibacter americanus'. Eur. J. Plant Pathol. 119:463-468.

33. Murashige, T., and Skoog, F. 1962. A revised medium for rapid growth and bioassays with tobacco cultures. Physiol. Plant. 15:473-497

34. Murashige, T., and Tucker, D. P. H. 1969. Growth factor requirements of citrus tissue culture. Pages 1155-1161 in: Proc. First Int. Citrus Symp.

35. Nariani, T. K., Raychaud, S. P., and Viswanat, S. M. 1971. Response of greening pathogen of citrus to certain tetracycline antibiotics. Curr. Sci. 40:552-552.

36. Nariani, T. K., Raychaud, S. P., and Viswanat, S. M. 1973. Tolerance to greening disease in certain citrus species. Curr. Sci. 42:513-514.

37. Sechler, A., Schuenzel, E. L., Cooke, P., Donnua, S., Thaveechai, N., Postnikova, E., Stone, A. L., Schneider, W. L., Damsteegt, V. D., and Schaad, N. W. 2009. Cultivation of 'Candidatus Liberibacter asiaticus', 'Ca. L. africanus', and 'Ca. L. americanus' associated with huanglongbing. Phytopathology 99:480-486.

38. Shashi, K., Kapur, S. P., and Kang, S. S. 1996. Chemo-trunk injection for the control of citrus greening. Indian J. Virol. 12:55-57.

39. Sundin, G. W., Werner, N. A., Yoder, K. S., and Aldwinckle, H. S. 2009. Field evaluation of biological control of fire blight in the eastern United States. Plant Dis. 93:386-394.

40. Tatineni, S., Sagaram, U. S., Gowda, S., Robertson, C. J., Dawson, W. O., Iwanami, T., and Wang, N. 2008. In planta distribution of 'Candidatus Liberibacter asiaticus' as revealed by polymerase chain reaction (PCR) and real-time PCR. Phytopathology 98:592-599.

41. Teixeira, D. C., Saillard, C., Couture, C., Martins, E. C., Wulff, N. A., Eveillard-Jagoueix, S., Yamamoto, P. T., Ayres, A. J., and Bové, J. M. 2008. Distribution and quantification of 'Candidatus Liberibacter americanus', agent of huanglongbing disease of citrus in São Paulo State, Brasil, in leaves of an affected sweet orange tree as determined by PCR. Mol. Cell. Probes 22:139-150.

42. Teixeira, D. D., Saillard, C., Eveillard, S., Danet, J. L., da Costa, P. I., Ayres, A. J., and Bové, J. M. 2005. 'Candidatus Liberibacter americanus', associated with citrus huanglongbing (greening disease) in São Paulo State, Brazil. Int. J. Syst. Evol. Microbiol. 55:1857-1862.

43. Tsiantos, J., Psallidas, P., and Chatzaki, A. 2003. Efficacy of alternatives to antibiotic chemicals for the control of fire blight of pears. Ann. Appl. Biol. 143:319-323.

44. ur Rahman, L., Ikenaga, T., and Kitamura, Y. 2004. Penicillin derivatives induce chemical structure-dependent root development, and application for plant transformation. Plant Cell Rep. 22:668-677.

45. Wang, Y., and Fang, K. T. 1996. Uniform design of experiments with mixtures. Sci. China Ser. A Math. Phys. Astron. 39:264-275. (In Chinese)

46. Wold, H. 1975. Soft modelling by latent variables; the nonlinear interactive partial least squares (NIPALS) approach. Pages 520-540 in: Perspective in Probability Statistics, Papers in Honour of M. S. Bartlett. J. Gani, ed. Academic Press, London.

47. Zhou, L. J., Gabriel, D. W., Duan, Y. P., Halbert, S. E., and Dixon, W. N. 2007. First report of dodder transmission of huanglongbing from naturally infected Murraya paniculata to citrus. Plant Dis. 91:227-227. 